\title{
A Subjetividade do Encarcerado, um Desafio para a Psicologia
}

\author{
The subjectivity of the imprisoned,
} a challenge for psychology

Maria da Glória Caxito Mameluque

Faculdades Integradas

Pitágoras de Montes

Claros-MG

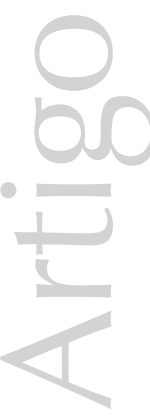




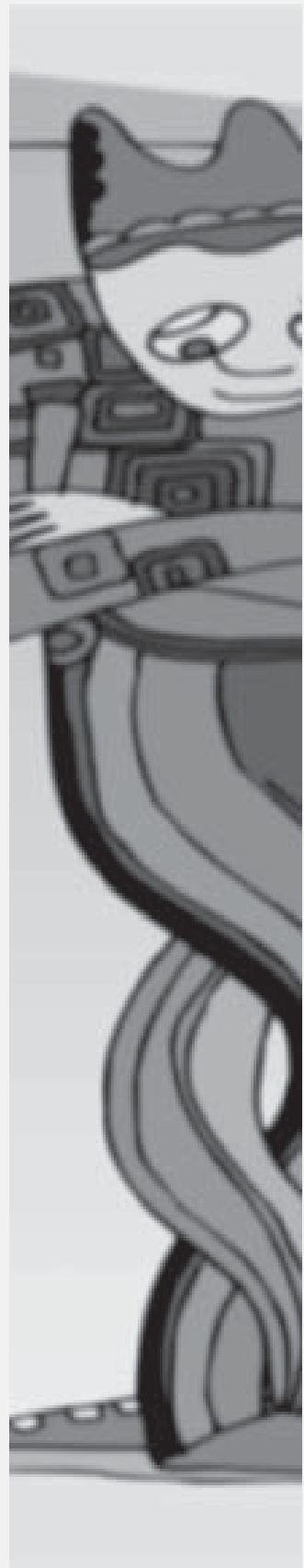

Resumo: Este trabalho, apresentado ao Prêmio Monográfico Pedro Parafita Bessa, instituído pelo Conselho Federal de Psicologia, em 2005, é uma reflexão sobre a subjetividade do encarcerado como um desafio para a Psicologia. O sistema prisional brasileiro é precário, com superpopulação carcerária, o que gera conflitos e rebeliões nos presídios e não favorece a ressocialização e a recuperação do ser humano. É urgente que se faça a leitura da dimensão subjetiva da vivência do encarceramento. Esse é o grande desafio para a Psicologia, pois a Psicologia jurídica é ainda uma prática emergente que carece de bibliografia, pesquisas e intercâmbio profissional. É mister que a Psicologia jurídica enfoque as determinações das práticas jurídicas sobre a subjetividade e elabore projetos, lançando mão de práticas que provoquem mudanças. Com o fortalecimento do projeto de compromisso social da Psicologia, esse desafio poderá ser superado, com grande benefício para a dignidade humana do encarcerado e para toda a sociedade.

Palavras-chave: subjetividade, sistema prisional, desafio, Psicologia jurídica.

Abstract: This work, presented to the Monographic prize Pedro Parafita Bessa, instituted by the Federal Council of Psychology in 2005, is a reflection about the subjectivity of the imprisoned as a challenge for Psychology. The prisional system is precarious, with prison super population, what generates conflicts and rebellions in the prisons. It doesn't favor the resocialization and the human being's recovery. It is urgent to reflect about the subjective dimension of the existence of imprisonment. This is the great challenge for Psychology, because Juridical Psychology is still an emerging practice with lack of bibliography, research and professional practice. It's necessary that this area of knowledge elaborates projects, using practices that can lead to changes. With the invigoration of the project of social commitment of Psychology, this challenge can be met, with great benefit for the human dignity of the imprisoned and for the whole society.

Key words : subjectivity, prisional system, challenge, Juridical Psychology. 
"... a subjetividade é a síntese singular e individual que cada um de nós vai construindo conforme vamos nos desenvolvendo e vivenciando as experiências da vida social e cultural; é uma síntese que nos identifica, de um lado, por ser única, e nos iguala, de outro lado, na medida em que os elementos que a constituem são experenciados no campo comum da objetividade social. Essa síntese - a subjetividade é o mundo de idéias, significados e emoções construído internamente pelo sujeito a partir de suas relações sociais, de suas vivências e de sua constituição biológica; é, também, fonte de suas manifestações afetivas e comportamentais."

Bock, Furtado e Teixeira, apud França
Pedro Parafita Bessa, pioneiro da Psicologia brasileira, criador do Curso de Psicologia da UFMG, atuou em toda a época militar contra as diversas formas de cerceamento e exclusão. Afastado da Universidade pelo Al-5, nunca pediu revisão de sua aposentadoria compulsória, quando dirigia a FAFICH Faculdade de Filosofia da UFMG.

Dez anos depois, recebeu o título de Professor Emérito da FAFICH, em Belo Horizonte, homologado por unanimidade pela Congregação. O motivo da cassação seria traduzido nas palavras do homenageado, naquela ocasião: "Para intimidar as universidades, pois dentro delas permanecia a crítica mais virulenta, mais fundada, mais constante e organizada à política e às medidas que eram tomadas."

Doutor Bessa, falecido em 17 de setembro de 2002, com 79 anos de idade, foi um pensador que fez, da reflexão, uma constante, e, do trabalho intelectual, uma paixão. Depois de cassado, acrescentou outra marca: a de quem soube superar com grandeza o sofrimento e a perseguição.

Neste trabalho, procuramos estabelecer uma relação entre subjetividade, sua importância como característica da pessoa humana e o encarceramento, que priva o homem de um dos seus maiores direitos - a liberdade, e a precariedade do sistema prisional brasileiro, que, juntos, representam um grande desafio para a Psicologia.

Com o desenvolvimento da Psicologia jurídica, que, segundo diversos autores, pode e necessita crescer, acredita-se que esse desafio será vencido ou minimizado.

\section{Subjetividade}

Vivemos numa sociedade de alta subjetividade que, cada vez mais, submete os fenômenos e os comportamentos à lógica subjetiva: a vida, a autoridade, a morte assumem relevo subjetivo, tornam-se fenômenos nos quais a experiência subjetiva passa a ser decisiva, sem que se chegue a compreender a diferença que realmente existe entre fenômeno e direito subjetivo. Nem sempre a carga de subjetividade que permeia um fenômeno ou um comportamento pode traduzir-se num direito do indivíduo de julgar e decidir por si só com relação ao fenômeno e ao próprio comportamento.

Bock, Furtado e Teixeira, apud França ( 2004, p.76), afirmam que:

a subjetividade é a síntese singular e individual que cada um de nós vai construindo conforme vamos nos desenvolvendo e vivenciando as experiências da vida social e cultural; é uma síntese que nos identifica, de um lado, por ser única, e nos iguala, de outro lado, na medida em que os elementos que a constituem são experenciados no campo comum da objetividade social. Essa síntese a subjetividade - é o mundo de idéias, significados e emoções construído internamente pelo sujeito a partir de suas relações sociais, de suas vivências e de sua constituição biológica; é, também, fonte de suas manifestações afetivas e comportamentais.

Segundo Foucault, apud França (2004, p.76), tanto as práticas jurídicas quanto as judiciárias são as mais importantes na determinação da subjetividade, pois, por meio delas, é possível estabelecer formas de relações entre os indivíduos. Tais práticas, submissas ao Estado, passam a interferir e a determinar as relações humanas e, em conseqüência, determinam a subjetividade do indivíduo.

A nossa subjetividade, por paradoxal que pareça, talvez seja a mais social de todas as características humanas. Ela, aparentemente tão individual e singular, só sobrevive enquanto puder ser social e diretamente ligada à 
sobrevivência do grupo social. É especialmente relevante que, pelo menos uma parcela do que é reconhecido como subjetividade - o self - seja produto da evolução das culturas.

Evely Fox Keller, em $O$ paradoxo da subjetividade científica, fala sobre a evolução da subjetividade, fazendo perguntas de natureza psicológica, relacionadas com o desenvolvimento do self e do outro. E o faz para compreender o sentido do sujeito e do objeto, o si mesmo e o outro, a evolução cognitiva de um e outro, o sujeito e o objeto em relação, o desenvolvimento, enfim, do conceito de gênero e do sentido do self como feminino e masculino.

As ciências que estudam as relações humanas requerem de nós uma orientação para um modelo ou ideal de self muito diferente e uma concepção diferente de subjetividade, não uma concepção que separe a relação entre o self e o outro, ou que se refira a uma relação a partir da perspectiva dessa divisão, mas que enraíze o sentido do self precisamente nas relações. Isso quer dizer que primeiro se dá a relação, e dela deriva o self, que se forma no processo de entrar e sair, de estar dentro e fora dessa relação.

A pergunta "O que é o self?" parece inocente à primeira vista, mas, ao refletirmos, torna-se evidente que há algo mais do que óbvio. Por alguma razão, o si mesmo foi, durante anos, um conceito central de Psicologia e psicoterapia. Em seu núcleo, essa pergunta é, ao mesmo tempo, metafísica e epistemológica. No sentido epistemológico, significa dizer que coisas tais como o si mesmo podem ser conhecidas não só pelo próprio, como também pelos demais. Em conseqüência, o self pode ser observado, medido, quantificado. Essa noção ganhou grande força na Psicologia moderna. "O que é o self?" implica a existência de algo central à humanidade, um núcleo fundamental inerente à condição humana, e essa essência o distingue de todas as demais substâncias conhecíveis e observáveis.

\section{Encarceramento}

Segundo Michel Foucault, a formação do sistema carcerário data de 22 de janeiro de 1840, data da abertura oficial de Mettray. Ele explica que o até então denominado processo punitivo, ligado à idéia de castigo, transformouse com a introdução e evolução do sistema carcerário em técnica penitenciária, agora direcionada à idéia de adestramento. Assim foi a técnica aplicada na mais célebre casa de correição - como eram denominadas as primeiras prisões, a Colônia de Mettray, inaugurada em Paris, no ano de 1839. Ligando a idéia de punir à de educar, os internos eram submetidos a trabalho forçado, instrução primária e religiosa. Cita ele a morte de uma criança, naquela Colônia, chamando-a de "primeiro santo penitenciário", e afirmando que muitos outros o seguiram, sem dúvida, e muitos dos colonos costumavam dizer, para fazer o elogio da nova política punitiva do corpo: "Preferíamos as pancadas, mas a cela é melhor para nós." Metray era a forma disciplinar mais intensa, o modelo em que se concentravam todas as tecnologias coercitivas do comportamento. A mínima desobediência era castigada, e o melhor meio de evitar delitos mais graves era punir severamente as mais leves faltas, reprimindo-se qualquer palavra inútil.

Mettray, como modelo punitivo, estava no limite da penalidade estrita. Foi a mais famosa de toda uma série de instituições que, bem além das fronteiras do Direito penal, constituíram o que se poderia chamar o arquipélago carcerário.

Para Foucault, foi então que se deu o nascimento do sistema prisional; não em 1810, e com o Código Penal, nem mesmo em 1824, com a lei que estabelecia o princípio do internamento celular, e não escolheu o ano 
"Damiens fora condenado, em 2 de março de 1757, a pedir perdão publicamente, diante da porta principal da lgreja de Paris, levado e acompanhado numa carroça, nu, de camisola, carregando uma tocha de cera acesa... em seguida, atenazado nos mamilos, braços, coxas e barrigas das pernas; sua mão direita segurava a faca com que cometeu o dito parricídio, queimada com fogo de enxofre, e, às partes em que será atenazado, aplicar-se-ão chumbo derretido, óleo fervente, piche em fogo, cera e enxofre derretidos conjuntamente, e, a seguir, seu corpo será puxado e desmembrado por quatro cavalos e seus membrose corpo consumidos ao fogo, reduzidos a cinzas..."

Foucault
1838, quando foram publicados os livros de Charles Lucas, Moreau - Christophe e Faucher sobre a reforma das prisões. Mettray era, sobretudo, um exemplo na especificidade que Ihe é reconhecida na operação de adestramento. A certidão de nascimento da Psicologia científica data dessa época.

Houve ainda as seções agrícolas das casas centrais, as colônias para crianças pobres, abandonadas e vazias, os refúgios de caridade destinados às moças culpadas, as colônias penitenciárias. Afastando-se sempre mais da penalidade propriamente dita, a forma de prisão se dilui lentamente antes de desaparecer por completo. Na justiça penal, a prisão transformou o processo punitivo em técnica penitenciária.

Fazendo uma retrospectiva das penas que antecederam o encarceramento, voltamos a 1757, quando havia o suplício:

Damiens fora condenado, em 2 de março de 1757, a pedir perdão publicamente, diante da porta principal da Igreja de Paris, levado e acompanhado numa carroça, nu, de camisola, carregando uma tocha de cera acesa... em seguida, atenazado nos mamilos, braços, coxas e barrigas das pernas; sua mão direita segurava a faca com que cometeu o dito parricídio, queimada com fogo de enxofre, e, às partes em que será atenazado, aplicar-se-ão chumbo derretido, óleo fervente, piche em fogo, cera e enxofre derretidos conjuntamente, e, a seguir, seu corpo será puxado e desmembrado por quatro cavalos e seus membros e corpo consumidos ao fogo, reduzidos a cinzas..." (Foucault, 1987, p. 9)

Foucault continua a narrar com detalhes as atrocidades cometidas contra os assassinos àquela época. Posteriormente foram aplicadas, na Europa e nos Estados Unidos, outras formas de castigo.
No fim do século XVIII e início do XIX, a despeito de ainda existirem grandes fogueiras, a melancólica festa da punição vai se extinguindo, e foi se suprimindo o espetáculo punitivo. A confissão pública dos crimes foi abolida na França, pela primeira vez, em 1791, mas foi restabelecida e novamente abolida em 1830. O pelourinho foi extinto em 1789. Algumas províncias americanas obrigavam os condenados a fazerem trabalhos forçados, com coleiras de ferro, em vestes multicores, grilhetas nos pés, prática que foi eliminada no fim do século XVIII.

O suplício da exposição do condenado foi mantido na França até 1831, apesar das críticas violentas, sendo finalmente abolida em abril de 1848; a punição, pouco a pouco, deixou de ser um espetáculo público, o que tinha um cunho negativo; ficou a suspeita de que tal rito mantinha, com o crime, afinidade espúria, igualando-o ou ultrapassando-o em selvageria, acostumando os espectadores a cenas de ferocidade e mostrando-lhes a freqüência dos crimes, o que fazia o carrasco se parecer a um criminoso e os juízes a assassinos, invertendose os papéis.

Beccaria, citado por Foucault (1987), afirma que "o assassinato, que nos é apresentado como um crime horrível, vemo-lo sendo cometido friamente, sem remorsos."

A punição foi se tornando a parte mais velada do processo penal. O desaparecimento do suplício significa que se elimina o domínio sobre o corpo. Rush, apud Foucault, assim diz:

"Só posso esperar que não esteja longe o tempo em que as forcas, o pelourinho, o patíbulo, o chicote, a roda, serão considerados, na história dos suplícios, marcas da barbárie dos séculos e dos países e provas da fraca influência da razão e da religião sobre o espírito humano."

A marca a ferro quente foi abolida na Inglaterra (1834) e na França (1832); o chicote ainda 
permanecia em alguns sistemas penais. Várias outras formas de punição foram sendo adotadas no percurso da História: a forca e a guilhotina foram utilizadas a partir de março de 1792. A morte é reduzida a um acontecimento visível, mas instantâneo. A guilhotina suprime a vida, tal como a prisão suprime a liberdade, quase sem tocar no corpo. Ainda sobreviveu algo dos suplícios quando, na França, os parricidas eram conduzidos ao cadafalso cobertos por um véu negro, e, até 1832, se lhes cortava a mão.

Em princípios do século XIX, desaparece, enfim, o grande espetáculo da punição física. O afrouxamento da severidade penal, no decorrer dos últimos séculos, é um fenômeno bem conhecido dos historiadores do Direito. É nesse período que se dá a passagem a uma penalidade de detenção. A prisão, peça essencial no conjunto das punições, marca certamente um momento importante na história da justiça penal. Apesar de ser uma novidade, surgiu tão ligada ao funcionamento da sociedade que relegou ao esquecimento todas as outras formas de punição que os reformadores imaginaram. O que fez surgir o encarceramento foi o progresso das idéias e a educação dos costumes.

Segundo Foucault (1987), a prisão é um quartel, uma escola sem indulgência, uma oficina sombria, mas, no fundo, nada tem de qualitativamente diferente. Esse duplo fundamento jurídico-econômico, por um lado, técnico-disciplinar por outro, fez a prisão aparecer como a forma mais imediata e mais civilizada de todas as penas.

Se considerarmos a evolução da pena, desde o suplício dos condenados do século XVIII até o encarceramento atual, podemos perceber o progresso de que fala Foucault. A obviedade da prisão se fundamenta também em seu papel, suposto ou exigido, de aparelho para transformar os indivíduos.

As penas corporais e infamantes, como a morte, o esquartejamento, os açoites, o degredo e a declaração de infâmia, eram aplicadas sob o pretexto de uma ideologia da salvação dos costumes sociais e religiosos ditados pelos poderosos.

No Brasil, com a primeira Constituição Federal (25/03/1824), o artigo 179 proclamava a inviolabilidade dos direitos civis e políticos dos cidadãos, tendo por base a liberdade, a segurança individual e a propriedade. Declarou abolidos os açoites, a tortura, a marca de ferro quente e as demais penas cruéis. A prisão passou a ser não só instrumento de castigo e expiação, mas "fonte de emenda e de reforma moral para o condenado."

Em 1830, foi sancionado, pelo Imperador D. Pedro I, o Código Criminal do Império, que previa onze classes de penas: morte, galés, prisão com trabalho, prisão simples, banimento, degredo, desterro, multa, suspensão do emprego, perda do emprego e açoites, esta última abolida em 15/10/1886. Proclamada a República, em 15/11/1889, foi elaborado um novo Código Penal que trouxe grandes transformações para o sistema penal. O Código de 1890 previa as seguintes modalidades: prisão celular, reclusão em fortalezas, prisão com trabalho obrigatório e prisão disciplinar para menores. Nesse momento, houve grande influência do positivismo na reformulação do ordenamento legal, insuficiente para conter o avanço da criminalidade. A Antropologia, a Sociologia e a psiquiatria entusiasmaram os penalistas brasileiros. Em 1927, foi divulgado o projeto do Código Penal, de autoria do Desembargador Virgílio de Sá Pereira, que dividia as penas em principais e acessórias. Após muitos debates, o Código Penal foi finalmente publicado em 31/12/1940. Instituiu a pena de reclusão (no máximo em trinta anos) e a detenção (no máximo em três anos) como as espécies de penas privativas da liberdade. Após a Segunda Guerra, apesar dos avanços da legislação em matéria de proteção do indivíduo contra o poder punitivo do Estado,
"Só posso esperar que não esteja longe o tempo em que as forcas, o pelourinho, 0 patíbulo, o chicote, a roda, serão considerados, na história dos suplícios, marcas da barbárie dos séculos e dos países e provas da fraca influência da razão e da religião sobre o espírito humano."

Foucault 
as penas privativas da liberdade foram consideradas a espinha dorsal do sistema e conservadas até hoje.

Ao longo de quarenta anos, é mantida a pena de prisão como a defesa avançada da sociedade. Cerca de duzentas e sessenta infrações recebem a cominação de pena privativa da liberdade, com maior número para a detenção.

Segundo Dotti (1998, p.104), a prisão tem sido, nos últimos séculos, a esperança das estruturas formais do Direito para combater a criminalidade, mas a degradação do sistema penitenciário a níveis intoleráveis vem sendo freqüentemente a prova de que os presídios brasileiros são verdadeiros depósitos de pessoas e permanentes fatores criminógenos. A sobrecarga das populações carcerárias é uma denúncia freqüente na doutrina, nas comissões de inquérito parlamentar e nos relatórios oficiais. A sistemática violação da intimidade do preso, com as naturais conseqüências ofensivas ao patrimônio físico, moral e espiritual, compõe um trecho significativo dessa odisséia e faz lembrar que antes, como agora, nada mudou. Carnelutti, apud Dotti, assim definiu esse aspecto do drama carcerário: "O recluso deixa de sentir-se um homem. O signo do homem é seu nome, e o recluso já não tem nome. A essência do homem é a individualidade, e o recluso já não tem individualidade."

Relatando as suas memórias do cárcere, na intensidade dos maiores sofrimentos, Dostoiewski afirmou que o famoso sistema celular só atinge um fim enganador, aparente. Suga a seiva vital do indivíduo, enfraqueceIhe a alma, amesquinha-o, aterroriza-o, e, no fim, apresenta-no-lo como modelo de correção, de arrependimento, uma múmia moralmente dissecada e semilouca.
A transição da pena privativa da liberdade para outras sanções implica uma reforma sistemática, cujas bases não podem subsistir se o Estado se nega a Ihes dar reconhecimento e proteção.

\section{Sistema prisional}

O sistema prisional brasileiro, que causa profunda e justificada preocupação devido à crescente criminalidade, não poderá resolverse com a modificação de leis, o acréscimo de penas e a construção de penitenciárias. A segurança depende muito mais de construir escolas, oferecer trabalho, educação e saúde a todos os cidadãos. A preocupação com o aumento da segurança apenas pela prisão, sem o seu objetivo maior - a ressocialização, na busca de soluções para seus efeitos, e não para suas causas.

A Lei de Execução Penal no 7.210, de 11 de julho de 1984, alterada pela Lei no 10.792 , de $01 / 12 / 2003$, não precisaria ser alterada, pois foi fruto de acurados estudos dos maiores juristas brasileiros, dentro dos objetivos da pena: a reeducação e a ressocialização do indivíduo. No entanto, todos reconhecem que a prisão, como é hoje aplicada, em jaulas e nos depósitos de homens e mulheres, não oferece jamais as desejáveis e legais soluções.

Ao fazer-se um estudo do sistema prisional, é mister que se distinga sistema penitenciário e regime penitenciário. O primeiro são corpos dessas doutrinas que se realizam através de formas políticas e sociais constitutivas das prisões; o segundo são formas de administração das prisões e os modos pelos quais se executam as penas.

Os sistemas penitenciários são: sistema filadélfico (1790), que preconizava o isolamento celular; o sistema auburniano (1818), baseado no trabalho coletivo sob silêncio absoluto, e os sistemas progressivos, como o modelo inglês, em três períodos: isolamento celular diurno e noturno, o trabalho 
em comum e a liberdade condicional, e o modelo irlandês, que aperfeiçoou o modelo inglês e que constava de isolamento celular diurno e noturno, isolamento noturno e trabalho diurno, período intermediário, com trabalho ao ar livre e liberdade condicional. Ainda completando o sistema penitenciário, existem os reformatórios, destinados a adolescentes e jovens infratores (Prado, 2002, p.472).

A Lei de Execução Penal vigente define os estabelecimentos penitenciários:

I - Cadeia pública ou presídio, destinado à custódia dos presos à disposição do juiz processante ; |l Penitenciária, para o sentenciado em regime fechado ; III - Colônia agrícola industrial ou similar, para o sentenciado em regime aberto; IV - Casa do albergado, para o sentenciado em regime aberto; $\mathrm{V}$ Centro de reeducação do jovem adulto ; VI - Centro de observação para realização de exame criminológico; VII - Hospital de custódia e tratamento psiquiátrico, para inimputáveis e semi-imputáveis.

O artigo 33 do Código Penal prevê pena de reclusão a ser cumprida em regime fechado, semi-aberto ou aberto, e a de detenção, em regime semi-aberto ou aberto.

Diante da precariedade do sistema prisional, tendo em vista o crescimento da população carcerária em todo o País e o conseqüente aumento dos conflitos gerados pelas condições precárias de vida nas superlotadas prisões, torna-se relevante estabelecer programas que possam agenciar produtivamente as forças desses homens em direção a seu desenvolvimento como cidadãos.

A permanência de presos sentenciados nas cadeias públicas e o ócio nas penitenciárias são certamente cultura fácil para a continuidade da vida delituosa. A priorização da custódia, em detrimento de um atendimento mais humanizado, tem contribuído para a revolta e a violência que vem assolando o sistema prisional em nosso país.

Vários programas têm surgido com o objetivo de sanar ou minimizar essa situação. No ano 1972, um grupo de pessoas, preocupadas com o grave problema das prisões em São José dos Campos, SP, decidiu pesquisar, no próprio presídio e no acervo da Faculdade do Vale do Paraíba, a situação em nível nacional. Diante do resultado alarmante que encontraram, iniciou-se um trabalho que se desenvolveria paulatinamente em busca de métodos mais adequados, que humanizasse a prisão e preparasse o preso para seu regresso ao convívio social. Descobriram, através da pesquisa, que 97\% (noventa e sete por cento) dos presos eram fruto de famílias desestruturadas, ilustrados na tabela 1.

Tabela 1- Perfil dos encarcerados em dados percentuais

\begin{tabular}{lll} 
1. & Reincidência & $86 \%$ \\
\hline 2. & Crimes praticados sob efeito de drogas & $80 \%$ \\
\hline 3. & População carcerária usuária de droga & $60 \%$ \\
\hline 4. & População entre dezoito e vinte e oito anos de idade & $60 \%$ \\
\hline 5. & Completam vinte e oito anos cumprindo pena & $20 \%$ \\
\hline 6. & Religião de origem: católica & $81 \%$ \\
\hline 7. & Apontam como causa de crime a família desestruturada & $97 \%$ \\
8. & Analfabetos ou semi-alfabetizados & $75 \%$ \\
\hline 9. & Sem profissão definida & $87 \%$ \\
10. & Casados & $18 \%$ \\
\hline 11. & Amasiados & $38 \%$ \\
\hline 12. Solteiros & $44 \%$
\end{tabular}


Ainda nessa pesquisa, foi detectada grande promiscuidade, com destaque para a ociosidade, a violência, a falta de confiança, a ausência da família, os sentimentos de autopunição e culpa, a perda da auto-estima, o sentimento de inferioridade e a ausência de esperança (Ottoboni, p. 2001).

Desse estudo, e com o apoio das autoridades, surgiu o método APAC - Associação de Proteção e Assistência aos Condenados, que representa uma revolução no sistema penitenciário, segundo seu criador, Mario Ottoboni. O método APAC consiste em atos religiosos, palestras de valorização humana, biblioteca, instituição de voluntários padrinhos, pesquisas sociais (conhecer as causas), representantes de cela, faxinas e outros trabalhos, reunião de grupo, concurso de composição e higiene das celas, contato com a família, conselho de sinceridade e solidariedade dos recuperandos.

Esse método tem atingido grande número de estabelecimentos penais em todo o Brasil. Os presos em regime fechado passam a cumprir pena no estágio inicial, que se distingue pela separação de cela e pelos estímulos criados. Este acontece em regime fechado e procurase desenvolver o senso de responsabilidade do preso; no segundo estágio (regime semiaberto), os presos ajudam nos serviços burocráticos da própria APAC. Depoimentos de várias autoridades atestam a validade do método APAC, como o do Desembargador Joaquim Alves de Andrade, do Tribunal de Justiça de Minas Gerais: "A sinceridade, a solidariedade, o amor à justiça e uma conduta irrepreensível são armas usadas para mudar a cabeça do preso, reciclando seus valores e potencializando suas qualidades." ${ }^{1}$

A filosofia da APAC consiste em que, enquanto o sistema penitenciário praticamente mata o homem e o criminoso que existe nele em razão de suas falhas e mazelas, a APAC propugna por "matar o criminoso e salvar o homem."
O método socializador empregado pela APAC tem alcançado grande repercussão no Brasil e no exterior. Hoje mais de cento e vinte entidades funcionam em doze Estados brasileiros e até no exterior (Argentina, Equador, Coréia do Sul e Rússia). Muitos são os depoimentos deixados nos livros de visitantes do presídio modelo da APAC, em São José dos Campos, SP.

\section{Subjetividade,}

\section{encarceramento e sistema prisional: desafios para a psicologia}

"Qual a subjetividade para o século XXI ?" Márcio de F. Giovannetti, presidente da Sociedade Brasileira de Psicanálise, assim questiona a todos, em texto publicado no site da Sociedade Brasileira para o Progresso da Ciência. Se, no início do século XX, Freud chocou o mundo científico ao descrever o homem sendo movido por suas paixões inconscientes, conceituando o sujeito desejante e enfatizando a natureza traumática de sua sexualidade e de sua identidade, é fundamental que o psicanalista de hoje possa repensar, a partir do contexto atual, a subjetividade emergente deste novo século.

Normalmente entende-se por sujeito o indivíduo que é capaz de agir por si mesmo, isto é, capaz de pensar, decidir e atuar conforme a sua própria decisão. Sendo assim, a subjetividade engloba todas as peculiaridades imanentes à condição de ser sujeito, envolvendo as capacidades sensoriais, afetivas, imaginativas e racionais de tal pessoa. $\mathrm{Na}$ verdade, toda pessoa é uma complexa unidade natural e cultural. Mais que um corpo com funções biológicas e psicológicas com capacidade de transformar o seu meio pelo trabalho e pela linguagem, o ser humano é uma unidade de necessidades, desejos, sentimentos, angústias, temores imaginários, racionalidade e paixões. Da mesma forma, Criminal, maio de 2005. Governo do Estado de Minas Gerais. 
como não podemos considerar o homem apenas um animal racional, também não podemos reduzir a subjetividade a uma dimensão meramente cognitiva, a uma consciência, desconsiderando todas as demais facetas da complexa interioridade de cada um. Essa subjetividade é uma espécie de argila que vai sendo modelada sob a cultura dominante de cada sociedade.

Segundo Carl Rogers (1983, p. 40), a prática, a teoria e a pesquisa deixam claro que a abordagem centrada na pessoa baseia-se na confiança em todos os seres humanos e em todos os organismos. Para ele, em cada organismo, não importa em qual nível, há um fluxo subjacente de movimento em direção à realização construtiva das possibilidades que Ihe são inerentes e, em especial, nos seres humanos, uma tendência realizadora.

Demonstrado está que o atual sistema prisional brasileiro em nada favorece a ressocialização e a recuperação do ser humano, pelo que já foi exposto.

Embora já tenha desaparecido o corpo supliciado, esquartejado, amputado, marcado a ferro no rosto ou no ombro, exposto vivo ou morto (Foucault, 1997, p.14), o essencial passa a ser corrigir, reeducar, curar. Segundo ele, há mesmo alguns que identificam a prisão com o hospital, o preso com o doente e a pena com o tratamento. O castigo passa da arte de causar sofrimentos insuportáveis a uma economia dos direitos suspensos.

A presidente do Conselho Federal de Psicologia, Ana Bock, em discurso de abertura do XIII Plenário do Conselho Federal de Psicologia, assim se expressou:

Por fim, gostaria de salientar que nossa utopia é pôr fim aos encarceramentos. Ninguém pode "melhorar" em situação de encarceramento. Sabemos que saúde psicológica se produz com laços sociais fortalecidos, com acolhimento, com possibilidade de fortalecimento do sujeito, com empoderamento, com ampliação da capacidade de intervenção transformadora da realidade. Em presídios, manicômios, Febens, dificilmente conseguiremos esse intento. Mas sabemos também que a transformação social não se faz da noite para o dia, e que precisamos estar lá, nesses diversos locais, para participar da sua transformação. Estamos e estaremos trabalhando no sistema prisional; comprometemo-nos a fazer, do nosso trabalho nesses espaços, uma contribuição crítica e respeitosa, tecnicamente competente e ética. Sabemos que há uma leitura a ser feita que é de nossa competência: a leitura da dimensão subjetiva da vivência do encarceramento.

Diante dessa posição, surge um questionamento: como está sendo tratada a subjetividade do encarcerado pelo psicólogo jurídico? No caso da APAC, que é um método de humanização da pena, como vem sendo tratada essa subjetividade?

Rogers (1983, p.50), no seu trabalho como terapeuta e facilitador, descobriu atitudes comprovadamente eficientes na promoção de mudanças construtivas na personalidade e no comportamento dos indivíduos. Assim, as pessoas desenvolvem maior autocompreensão, maior autoconfiança e maior capacidade de escolher os comportamentos que terão. São mais livres para ser e transformar-se. A tendência à autorealização é ativa no ser humano. E finaliza: "Quando criamos um clima psicológico que permite que as pessoas sejam, estamos descobrindo uma tendência para se tornar toda a complexidade de que o organismo é capaz."

Mas, no ambiente prisional, e da forma como é desenvolvida a Psicologia jurídica, é possível que isso ocorra?

Aí está o grande desafio para a Psicologia, pois, até agora, a Psicologia jurídica é uma área carente de bibliografia, pesquisas e
2 http:/www.pol.org.br debate - acesso em 28/ 11 , às $23 \mathrm{~h} 30 \mathrm{~m}$. 
intercâmbio profissional. Na maioria dos casos, ainda está atrelada à utilização de testes e entrevistas, elaboração de laudos e pareceres para subsidiar decisões judiciais. Poderia ir além: elaborar projetos, lançar mão de práticas de orientação que provocassem mudanças, transcendendo a prática pericial e questionando o papel que lhe é atribuído.

Conforme a legislação vigente, o papel do psicólogo jurídico nas penitenciárias é caracterizado pela realização de exames para classificação e laudos sobre o comportamento dos detentos. Essas atividades servem para orientar progressões e regressões de regime ou punições por faltas disciplinares. É mister que a Psicologia jurídica enfoque as determinações das práticas jurídicas sobre a subjetividade.

Fátima França, em Reflexões sobre a Psicologia jurídica e seu panorama no Brasil, cita sua experiência como psicóloga de um programa de assistência aos egressos do sistema penitenciário. Segundo ela, diariamente testemunhava as conseqüências do seu encarceramento e percebia que não se tratava apenas dos comportamentos adquiridos na prisão, mas de uma nova forma de pensar e sentir; eram marcas impregnadas na subjetividade dos egressos que iriam determinar a forma de suas existências. Afirma que, para a Psicologia jurídica, não há nenhum problema em responder as perguntas e demandas do jurídico, mas não pode ocorrer a sua estagnação nesse tipo de relação.

\section{Conclusão}

A subjetividade, o encarceramento e o sistema prisional são, sem dúvida, um grande desafio para a Psicologia. Sabemos da triste realidade e do estado atual de horror do nosso sistema penitenciário. Vislumbramos uma pequena luz de esperança nos novos métodos de humanização da pena que têm surgido timidamente, como o método APAC. O
Conselho Federal de Psicologia, conforme sua presidente, está construindo referências para as práticas profissionais, mas reconhece que um dos maiores desafios é o modo de fazer isso.

A Psicologia jurídica é uma prática emergente em nosso país. Seu objeto é o comportamento humano no âmbito do mundo jurídico. Bock, Furtado e Teixeira, apud França (2004, p.76), afirmam que a Psicologia, por ser uma ciência nova, "não teve tempo ainda de apresentar teorias acabadas e definitivas, que permitam determinar com maior precisão seu objeto de estudo." Disso resulta a diversidade de objetos da Psicologia: o comportamento, o inconsciente, a personalidade e a identidade, entre outros.

Segundo França (2004, p.77), a Psicologia jurídica deveria enfocar também as determinações das práticas jurídicas sobre a subjetividade; não mais enfocaria apenas o comportamento do indivíduo, indo além das expectativas que o jurídico possui em relação a essa Psicologia, e afirma que, para esta, não há nenhum problema em responder as demandas do jurídico. No entanto, ela deve transcender as solicitações do mundo jurídico e repensar se é possível responder, sob o ponto de vista psicológico, todas as perguntas que Ihe são lançadas.

A Psicologia jurídica deve ir além do estudo de uma das manifestações da subjetividade, ou seja, o estudo do comportamento. Deveriam ainda ser objeto de estudo as conseqüências das ações jurídicas sobre o indivíduo. Assim se conclui que, com o desenvolvimento da Psicologia jurídica e com o fortalecimento do projeto de compromisso social da Psicologia, esse desafio será superado, com grande benefício para a dignidade humana do encarcerado e para toda a sociedade.

Há até mesmo a possibilidade de uma interlocução entre a psicanálise e a Psicologia 
631

jurídica. Textos de Freud, Lacan e Foucault apontam o fato de que o trabalho do psicólogo junto ao Poder Judiciário é uma possibilidade que já existe desde o momento em que se davam os primeiros passos na construção das teorias que embasavam o trabalho profissional do psicanalista. Obra recente, produzida pela Associação Psicanalítica de Porto Alegre, afirma estar aberta a possibilidade de diálogo entre psicanálise e Direito. ${ }^{3}$
Segundo França (2004), a Psicologia jurídica pode e necessita crescer, não só na quantidade de profissionais atuantes, na qualidade do trabalho desenvolvido por eles, mas também na intensificação da produção e publicação do conhecimento. Esse também é um desafio, mas existem outros em níveis metodológicos, epistemológicos e de compromisso social. Dessa forma, a subjetividade, o encarceramento e o sistema prisional deixarão de ser um desafio para a Psicologia.
3 BRAUER . J.F. Reflexão sobre a possibilidade de interlocução entre a psicanálise e a Psicologia forense.

copsa.cop.es/ congresoiberoa/juridica / p.19.htm
DOTTI, René Ariel. Bases e Alternativas para o Sistema de Penas. 2ª ed. São Paulo: Ed. Revista dos Tribunais, 1998.

FOUCAULT, Michel. Vigiar e Punir. 24aㅡ ed. Petrópolis, RJ : Vozes, 1987.

FRANÇA, Fátima. Reflexões sobre Psicologia Jurídica e seu Panorama no Brasil. In Psicologia: Teoria e Prática, vol.6, no 1, jan./jun. 2004.

KELLER, E.F. O Paradoxo da Subjetividade Científica. In Schnitman, D.F. (org). Novos Paradigmas, Cultura e Subjetividade. Porto Alegre : Artes Médicas, 1996.
Maria da Glória Caxito Mameluque Rua Lafetá, 166 - ap. 401 - Ed.Ciosa - Centro 39400-045 - Montes Claros - MG Fone: (38) 3212-2124 - Fone/fax: (38)3221-0767 E-mail:pedroglorinha@viamoc.com.br

Recebido 14/12/05 Reformulado 17/10/06 Aprovado 09/11/06

OTTOBONI, Mário. Ninguém é Irrecuperável. 2ª ed. São Paulo: Cidade Nova, 2001.

PRADO, L. R. Curso de Direito Penal Brasileiro, vol.1. 3ª ed. São Paulo: Editora Revista dos Tribunais, 2002.

ROGERS, Carl R. Um Jeito de Ser. São Paulo: Editora Pedagógica e Universitária, 1983.

http:// cienciaecultura.bvs.br/cielo acesso em 28.11.05 às $23 \mathrm{~h}$ 